\title{
A novel synthetic ursolic acid derivative inhibits growth and induces apoptosis in breast cancer cell lines
}

\author{
WEI LI ${ }^{1,2^{*}}$, HONGXIU ZHANG ${ }^{1,2^{*}}$, MINGXIU NIE ${ }^{1,2}$, WEI WANG ${ }^{3}$, ZONGTAO LIU $^{3}$, CESHI CHEN $^{4}$, \\ HAIJUN CHEN ${ }^{5}$, RONG LIU ${ }^{4}, \mathrm{ZULQARNAIN} \mathrm{BALOCH}^{2}$ and $\mathrm{KE} \mathrm{MA}^{6}$ \\ ${ }^{1}$ Department of Urology, The First People's Hospital of Yunnan Province, Kunming, Yunnan 650032; \\ ${ }^{2}$ Medical College of Kunming University of Science and Technology, Kunming, Yunnan 650500; \\ ${ }^{3}$ College of Pharmacy, Qingdao University, Qingdao, Shandong 266021; ${ }^{4}$ Key Laboratory of Animal Models and \\ Human Disease Mechanisms of Kunming Institute of Zoology, Chinese Academy of Sciences, Kunming, Yunnan 650223; \\ ${ }^{5}$ College of Chemistry, Fuzhou University, Fuzhou, Fujian 350116; ${ }^{6}$ College of Traditional Chinese Medicine, \\ Shandong University of Traditional Chinese Medicine, Jinan, Shandong 250355, P.R. China
}

Received June 6, 2016; Accepted November 2, 2017

DOI: $10.3892 / \mathrm{ol} .2017 .7578$

\begin{abstract}
The present study investigated the anticancer functions of ursolic acid (UA) and its novel derivatives, with a nitrogen-containing heterocyclic scaffold and the privileged fragment at the $\mathrm{C}-28$ position on apoptosis induction, cell proliferation and cell cycle in human BC lines. UA was chemically modified in the present study to increase its antitumor activity and bioavailability. A novel UA derivative, FZU3010, was synthesized using a nitrogen-containing heterocyclic scaffold and a privileged fragment at the C-28 position. Sulforhodimine B assays were used to measure the effect of UA and different concentrations of FZU3010 on the viability of breast cancer (BC) SUM149PT and HCC1937 cells. FZU3010 significantly repressed the proliferation of the two cancer cell lines in a dose-dependent manner, with a half-maximal inhibitory concentration of 4-6 $\mu \mathrm{M}$, and exhibited decreased cytotoxicity compared with vehicle-treated cell lines. The effect of FZU3010 on cell cycle distribution and cellular apoptosis was also investigated. The results of this investigation indicated that FZU3010 significantly increased the number of SUM149PT and breast cancer HCC1937 cells in the $\mathrm{G}_{0} / \mathrm{G}_{1}$ phase in a dose-dependent manner. Additionally, at a concentration of $5 \mu \mathrm{M}$, the capability of FZU3010 to induce BC apoptosis was significantly higher than the capability of UA.
\end{abstract}

Correspondence to: Dr Ke Ma, College of Traditional Chinese Medicine, Shandong University of Traditional Chinese Medicine, 4655 University Road, Changqing, Jinan, Shandong 250355, P.R. China

E-mail: make19880710@163.com

*Contributed equally

Key words: ursolic acid, breast cancer, FZU3010, proliferation, apoptosis
Thus, the results of the current study indicated that FZU3010 induced apoptosis in BC cells, together with induction of cell cycle arrest at the $S$ and $G_{0} / G_{1}$ phase. FZU3010 may therefore be considered as a potential therapeutic agent for the treatment of $\mathrm{BC}$.

\section{Introduction}

Breast cancer (BC) is an important global health problem (1). According to estimates by the American Cancer Society in 2015, BC is a common cause of cancer-associated mortality in females in the United States and is predicted to account for $29 \%$ of all new female cancer diagnoses (2). As with other types of cancer, $\mathrm{BC}$ occurs due to an interaction between a lifestyle factor (drinking alcohol, hormone replacement therapy during menopause and ionizing radiation) $(3,4)$ and a genetically susceptible host, such as in patients with breast cancer susceptibility protein family gene mutations (5-7). Current therapeutic options, including adjuvant chemotherapy, radiotherapy, hormone therapies and surgery are appropriate for patients with $\mathrm{BC}(8)$. These treatments have significant side effects, including decreased immunity, nausea, vomiting, anemia, leukopenia and myelosuppression (9). However, further investigation is required for developing better and more effective therapeutic agents.

A number of recently conducted studies have recognized several potential agents (10), biomarkers (11) and candidate pathways (12) that may be used to treat patients with BC. Among these approaches, cancer chemoprevention using synthetic or natural complexes to treat, slow, suppress or reverse the progression of tumorigenesis is one of the most promising anticancer strategies. A growing number of natural products and raw materials are being synthesized into potential therapeutic agents for the management of various types of cancer (10-12). Ursolic acid (UA) is a pentacyclic triterpenoid complex extracted from naturally growing herbs (13). Previous studies have demonstrated that UA has antiviral, antibacterial, immunomodulatory and hepatoprotective properties $(14,15)$. 
Several studies have confirmed that UA has anti-proliferative properties in a variety of cancer cell lines, including those of colorectal cancer (16), endometrial cancer (17), squamous skin cancer (18) and BC (19). Furthermore, UA exhibits a wide range of activities that have an effect on the development of cancer, including repression of proliferation, angiogenesis, invasion, metastasis, differentiation and induction of tumor cell apoptosis (20). However, the poor bioavailability and tumor-targeting specificity of UA limits its clinical application in $\mathrm{BC}$ treatment (21).

A wide range of chemically modified compounds of UA has been used to increase its bioavailability and antitumor efficacy (12). The combination of acyl piperazine moiety at C-28 has been demonstrated to improve the antitumor activity of UA derivatives $(22,23)$. Additionally, a number of studies have described that several UA modified derivatives at the C-3 and/or 17-COOH positions have significantly improved antitumor effects (24-26). Modifications at C-28 and C-3 of UA may therefore lead to improved anti-BC activity. The current study investigated the anticancer functions of UA and its novel derivatives, with a nitrogen-containing heterocyclic scaffold and the privileged fragment at the C-28 position on apoptosis induction, cell proliferation and cell cycle in human BC lines. The aim of the current study was to identify novel UA derivative compounds with limited side effects, high selectivity, low toxicity and improved anticancer activity.

\section{Materials and methods}

Preparation of UA derivative FZU3010. 3-acetyl UA (Sinopharm Chemical Reagent Co., Ltd., Shanghai, China) was produced by treating UA (TGI) with acetic anhydride in dry pyridine under the existing 4-dimethylaminopyridine at room temperature for $2 \mathrm{~h}$. 3-acetyl UA was treated with oxalyl chloride at room temperature for $3 \mathrm{~h}$ to produce an intermediary 28 -acyl chloride. This compound was then mixed at room temperature for $2 \mathrm{~h}$ with piperazine (Sinopharm Chemical Reagent Co., Ltd.) to synthesize FZU3010.

Cell culture. BC SUM149PT and HCC1937 cell lines were obtained from Key Laboratory of Animal Models and Human Disease Mechanisms at the Kunming Institute of Zoology (Chinese Academy of Sciences, Kunming, China). SUM149PT cells were maintained in RPMI-1640 (Gibco; Thermo Fisher Scientific, Inc., Waltham, MA, USA) and HCC1937 cells were cultured in Ham's F12 medium (Lonza Group, Ltd., Basel, Switzerland) at $37^{\circ} \mathrm{C}$. The medium was supplemented with $1 \%$ antibiotics $(100 \mathrm{mg} / \mathrm{ml}$ streptomycin sulfate and $100 \mathrm{U} / \mathrm{ml}$ penicillin) and 10\% fetal bovine serum (FBS; GE Healthcare Life Sciences, Logan, UT, USA). Cells were cultivated at $37^{\circ} \mathrm{C}$ with a humidified atmosphere of $5 \% \mathrm{CO}_{2}$. Dimethyl sulfoxide (DMSO) was used to prepare the stock solutions and additional dilutions were produced using fresh culture medium. The concentration of DMSO was $1 \%$ in the final culture medium.

Cell viability/proliferation assay. Cell proliferation was determined using a sulforhodamine B (SRB) assay kit (Sigma-Aldrich; Merck KGaA, Darmstadt, Germany). SUM149PT and HCC1937 cells were cultured in 96-well plates at a density of 2,000 cells/well for $48 \mathrm{~h}$ at $37^{\circ} \mathrm{C}$. Cells were then treated with seven different concentrations of FZU3010 and UA $(1,2,4,6,8,10$ and $20 \mu \mathrm{M})$ for $48 \mathrm{~h}$; DMSO served as a negative control. Cells were fixed in $100 \mathrm{ml} 10 \%$ trichloroacetic acid for $1 \mathrm{~h}$ at $37^{\circ} \mathrm{C}$ and then washed with deionized water five times. Cells were stained for $5 \mathrm{~min}$ with $50 \mathrm{ml} 0.4 \%$ (W/V) SRB in $1 \%$ acetic acid in the dark at room temperature and the plates were then washed five times with $1 \%$ acetic acid prior to being dried. A total of $100 \mathrm{ml} 10 \mathrm{mM}$ Tris base was then added to each well. Optical densities were determined at a wavelength of $530 \mathrm{~nm}$ using a spectrophotometric plate reader. Cell viability values at different drug dosages were plotted and half-maximal inhibitory concentration $\left(\mathrm{IC}_{50}\right)$ values were obtained from the graphs created.

Cell cycle analysis. A cell-cycle cytotoxicity assay was used to determine the suppression of cancer cell development. SUM149PT and HCC1937 cells were seeded onto 96-well plates at a density of $1 \times 10^{4}$ cells/well and were treated for $24 \mathrm{~h}$ with FZU3010 (2.5 and $5 \mu \mathrm{M})$, UA $(5 \mu \mathrm{M})$ or $0.1 \%$ DMSO, which was used as a vehicle-treated control. SUM149PT and $\mathrm{HCC} 1937\left(1 \times 10^{4}\right)$ cells were collected using trypsinization and ice-cold PBS was then used to wash the cells. Cells were fixed with ice-cold $70 \%$ methanol overnight at $4^{\circ} \mathrm{C}$. All cells were centrifuged $\left(4^{\circ} \mathrm{C}, 13,000 \mathrm{x} \mathrm{g}\right)$ and placed in ice-cold PBS suspension prior to being incubated with RNase (Sigma-Aldrich; Merck KGaA) for $30 \mathrm{~min}$ at $37^{\circ} \mathrm{C}$. Cells were then stained with $1 \mathrm{mg} / \mathrm{ml}$ propidium iodide (PI) (Sigma-Aldrich; Merck KGaA) in the dark at $4^{\circ} \mathrm{C}$ for $30 \mathrm{~min}$. A FACScan flow cytometer 337452 Rev system (BD Biosciences, Franklin Lakes, NJ, USA) was then used to analyze cell cycle distribution. All data were analyzed using CELL Quest and ModFit LT software for Mac V1.01 (Verity Software House, Inc., Topsham, ME, USA).

Apoptosis analysis. The Annexin V-fluoroscein isothiocyanate (FITC)/PI test was used to determine the rate of apoptosis in the BC cell lines. Doxorubicin (DTX; Sigma-Aldrich; Merck $\mathrm{KGaA}$ ) served as a positive control. Cells were cultured in 6-well plates at a density of 2x106/well in 10\% FBS-Dulbecco's modified Eagle's medium (Gibco; Thermo Fisher Scientific, Inc.) and treated at room temperature with different concentrations of UA $(0,1.25,2.5$ or $5 \mu \mathrm{M})$ and $5 \mu \mathrm{M}$ DTX for $48 \mathrm{~h}$. Cold PBS was then used to wash the cells twice for $30 \mathrm{~min}$ and cells were resuspended into $1 \mathrm{X}$ binding buffer $(1.4 \mathrm{M} \mathrm{NaCl}$, $25 \mathrm{mM} \mathrm{CaCl}_{2}, 0.1 \mathrm{M}$ Hepes/ $\mathrm{NaOH} ; \mathrm{pH}$ 7.4) at a concentration of $1 \times 10^{6}$ cells $/ \mathrm{ml}$. A total of $100 \mu 1$ solution ( $1 \times 10^{5}$ cells) was transferred into a 5-ml culture tube and $5 \mu 1$ Annexin V-FITC (BD Biosciences) and $5 \mu \mathrm{l}$ PI was added to each tube. Cells were gently vortexed and incubated at room temperature for $30 \mathrm{~min}$ in the dark. A total of $200 \mathrm{ml}$ PBS was then added to each tube. A FACSCalibur flow cytometer with FACSLoader (BD Biosciences) was used to analyze the cells at emission and excitation wavelengths of 488 and $570 \mathrm{~nm}$, respectively. Apoptosis was determined using the Annexin V-FITC/PI apoptosis kit (Biovision, Inc., Milpitas, CA, USA) according to the manufacturers protocol as per the manufacturer's instructions.

Statistical analysis. Data are expressed as the mean \pm standard deviation from at least three experiments. One-way 


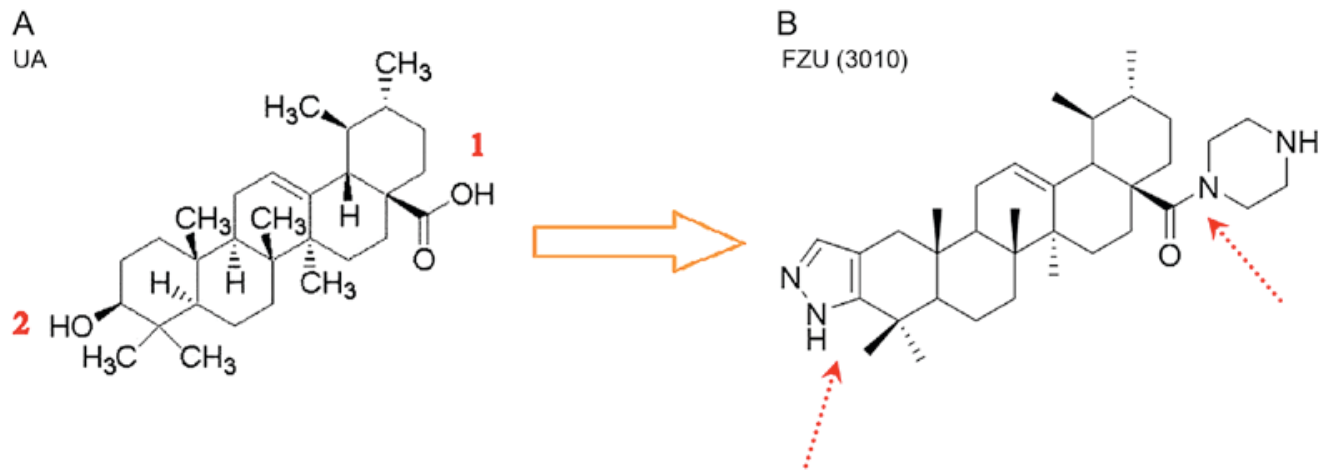

Figure 1. Synthesis of (A) ursolic acid (UA) derivative (B) FZU3010. 1, C-3 position of UA; 2, C-28 position of UA. Red arrows indicate chemical modifications of UA FZU3010.
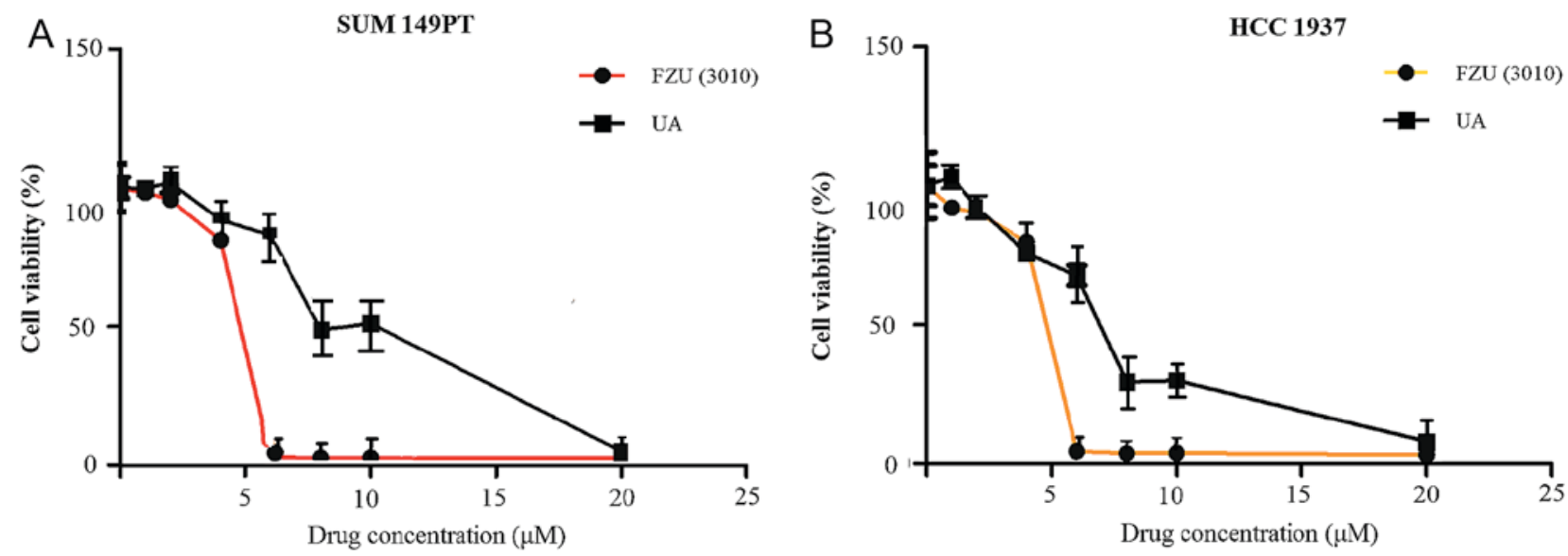

Figure 2. Dose-response curves of the anti-proliferative effect of FZU3010 and UA. A sulforhodamine B assay was used to determine the capability of FZU3010 and UA to inhibit the viability of SUM149PT and HCC1937 cells. FZU3010 $(0,1,2,4,6,8,10$ and $20 \mu \mathrm{M})$ and UA $(0,1,2,4,6,8,10$ and $20 \mu \mathrm{M})$ was used to treat (A) SUM149PT and (B) HCC1937 cells for $48 \mathrm{~h}$. Data are expressed as the mean \pm standard deviation from at least three experiments. Unpaired two-tailed test was used to compare differences between groups. UA, ursolic acid.

analysis of variance was used to analyze and compare multiple drug concentrations within the same group, and unpaired two-tailed tests were used to compare differences between groups. The least significant difference post hoc method was used to perform mean separations. $\mathrm{IC}_{50}$ concentrations/curves were calculated and drawn using Excel 2007 (Microsoft Corporation, Redmond, WA, USA). All statistical analyses were performed using SPSS 18.0 (SPSS, Inc., Chicago, IL, USA). $\mathrm{P}<0.05$ was determined to indicate statistically significant difference.

\section{Results}

Chemistry of FZU3010. UA was used as the parent compound in the present study and modifications were made to its structure at the C-3 position and C-28 position. Synthesis of the UA derivative FZU3010 is presented in Fig. 1.

Effect of UA and FZU3010 on cell viability. An SRB assay was used to determine the effect of FZU3010 and UA on the viability of SUM149PT and HCC1937 cells. Cells were incubated for $48 \mathrm{~h}$ with $0,1,2,4,6,8,10$ and $20 \mu \mathrm{M}$ FZU3010 or UA. The $\mathrm{IC}_{50}$ values for UA to suppress cell viability were 8-10 $\mu \mathrm{M}$ in the two cancer cell lines (Fig. 2). FZU3010 repressed the viability of the two cancer cell lines compared with the UA-treated cells and exhibited an $\mathrm{IC}_{50}$ of $4-6 \mu \mathrm{M}$. FZU3010 has also been demonstrated to be non-toxic to the normal human HELF cell line in previous studies $(27,28)$. Furthermore, the results of the present study were consistent with other findings that the $\mathrm{IC}_{50}$ of FZU3010 was 4-6 $\mu \mathrm{M}$ in the human body $(29,30)$.

Effect of FZU3010 on cell cycle distribution. The cell cycle consists of four different phases: $G_{0}$, which is a rest phase in which the cell stops dividing and has left the cell cycle; $\mathrm{G}_{1}$, which is a phase in which the cell prepares energy and material for DNA replication; S, which is the synthesis phase; G2, which is known as the interphase where preparation for the $\mathrm{M}$ phase occurs; and $\mathrm{M}$, which is a 'mitosis' phase, in which nuclear and cytoplasmic division occurs.

The FZU3010-induced suppression of cancer cell viability due to the arrest of cell cycle progression was confirmed using a cell-cycle cytotoxicity assay by treating SUM149PT and HCC1937 cells for $24 \mathrm{~h}$ with FZU3010 at different doses $(0,1.25,2.5$ or $5 \mu \mathrm{M})$, UA $(5 \mu \mathrm{M})$ and $0.1 \%$ supplemented DMSO medium, which served as a control (Fig. 3). The results demonstrated that FZU3010 administration significantly increased the percentage of cells in $\mathrm{G}_{0} / \mathrm{G}_{1}$ compared with the 
A
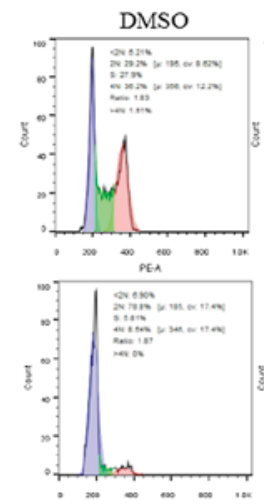

FZU 3010: $5 \mu \mathrm{M}$
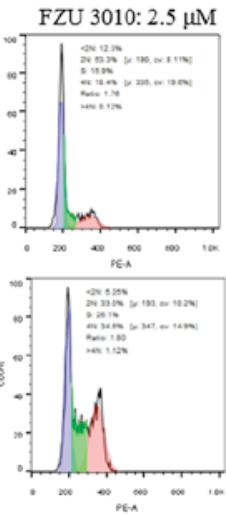

SUM 149PT

C

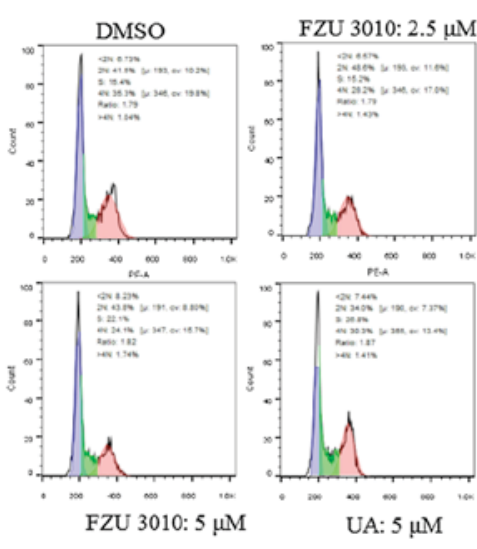

HCC 1937

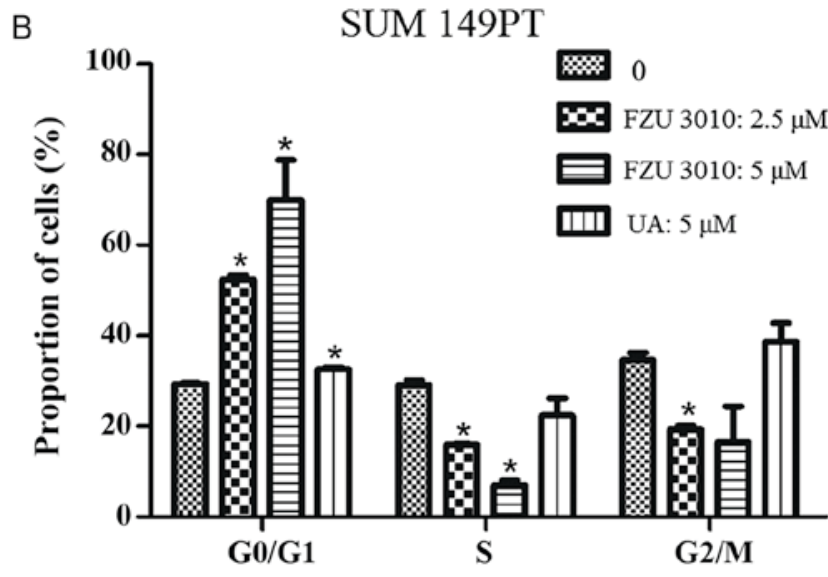

D

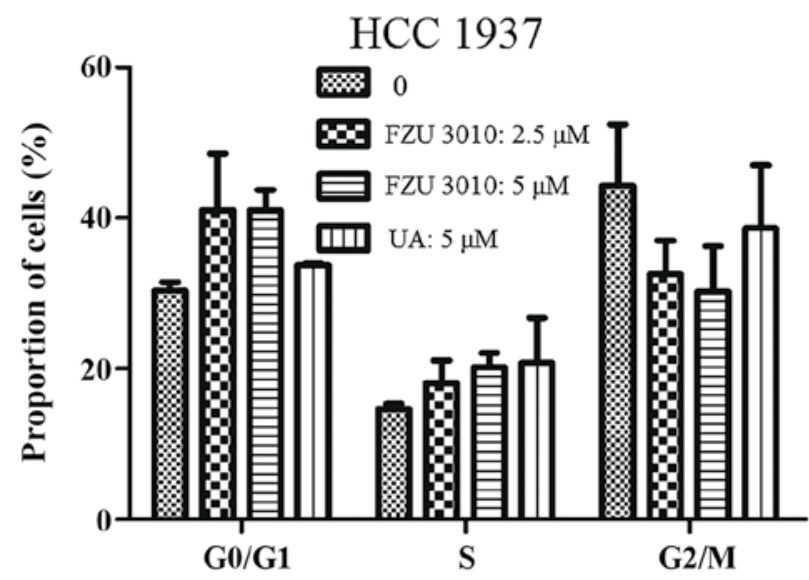

Figure 3. Effect of FZU3010 on cell cycle distribution. A cell-cycle cytotoxicity assay was performed by treating SUM149PT and HCC1937 cells for $24 \mathrm{~h}$ with FZU3010 $(0,2.5,5 \mu \mathrm{M}), \mathrm{UA}(5 \mu \mathrm{M})$ and medium containing $0.1 \%$ DMSO, which served as a vehicle-treated control. (A) Flow cytometry analysis of cell cycle distribution in SUM149PT cells and (B) quantification of flow cytometry analysis for SUM149PT cells. (C) Flow cytometry analysis of cell cycle distribution in HCC1937 cells and (D) quantification of flow cytometry analysis for HCC1937 cells. Data are expressed as the mean \pm standard deviation of at least three experiments. One-way analysis of variance was used to analyze multiple comparisons between different drug concentrations for the same group. ${ }^{*} \mathrm{P}<0.05 \mathrm{vs}$. normal control $(0 \mu \mathrm{M})$. UA, ursolic acid; DMSO, dimethyl sulfoxide.

DMSO-treated control SUM149PT cells. The arrest of $\mathrm{G}_{0} / \mathrm{G}_{1}$ was highest in cells treated with $5 \mu \mathrm{M}$ FZU3010.

Effect of FZU3010 on cell apoptosis. SUM149PT and HCC1937 cell apoptosis was investigated to validate the anticancer activity of FZU3010 using Annexin V-FITC/PI double staining, with the chemotherapy drug DTX serving as a positive control (Fig. 4). The number of apoptotic SUM149PT and HCC1937 cells was measured following treatment for $48 \mathrm{~h}$ with FZU3010 at concentrations of $0,1.25,2.5$ and $5 \mu \mathrm{M}$ and $\mathrm{UA}$ at a concentration of $5 \mu \mathrm{M}$, respectively. The percentage of Annexin V-positive SUM149PT and HCC1937 apoptotic cells was significantly increased following the administration with $5 \mu \mathrm{M}$ FZU3010 compared with cells treated with $0 \mu \mathrm{M}$ (normal control); however, the difference between cells treated with the lower concentrations of FZU3010 and the normal control cells was not significant. The capability of FZU3010 to induce apoptosis in SUM 149PT $(\mathrm{P}=0.008)$ and HCC $1937(\mathrm{P}=0.01)$ cells was significantly higher in cells treated with $5 \mu \mathrm{M}$ FZU3010 compared with cells treated with $5 \mu \mathrm{M}$ UA. Furthermore, the apoptotic cells in SUM149PT $(\mathrm{P}=0.049)$ and HCC 1937 $(\mathrm{P}=0.038)$ cells treated with $5 \mu \mathrm{M}$ FZU3010 were significantly increased compared with those treated with $5 \mu \mathrm{M}$ DTX.

\section{Discussion}

UA is a pentacyclic triterpenoid composite isolated from natural plants or traditional medicinal herbs, exhibiting a wide range of pharmacological activities (12-20). The anti-inflammatory and anti-oxidative functions of UA, including cardiovascular protection, neuroprotection and hepatoprotection, have been demonstrated previously (31). The anticancer activity of UA has also been reported in different types of cancer cell lines (10-12). UA is therefore an effective anticancer agent to which extensive structural changes have been made in order to further increase its anticancer activity (32). Several studies have reported that modified derivatives of UA with functional groups at the C-3 and/or C-28 positions exhibit significant bioactivity (33-35).

The results of the present study demonstrated that FZU3010 significantly repressed the viability of SUM149PT and $\mathrm{HCC} 1937$ cells with an $\mathrm{IC}_{50}$ of 4-6 $\mu \mathrm{M}$, exhibiting a lower cytotoxicity than DMSO-treated cell lines. This result indicates that the modification at $\mathrm{C}-28$ and $3-\mathrm{OH}$ in the UA core significantly increases the antitumor activities of UA. These results are consistent with a previous study by Chen et al (36), which demonstrated that the structural 
A
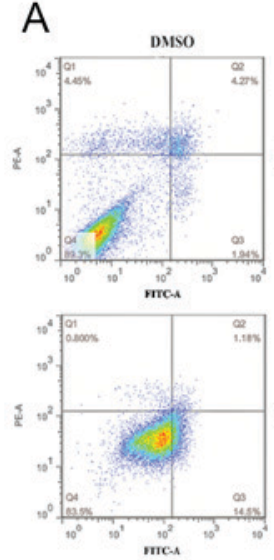

FZU3010 $5 \mu \mathrm{M}$
SUM 149PT
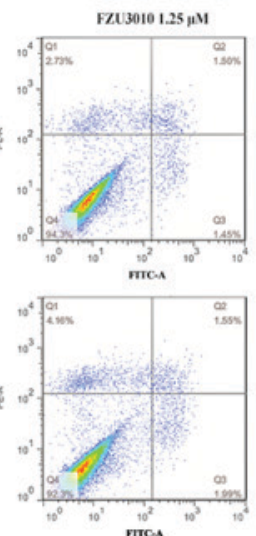

UA $5 \mu \mathrm{M}$
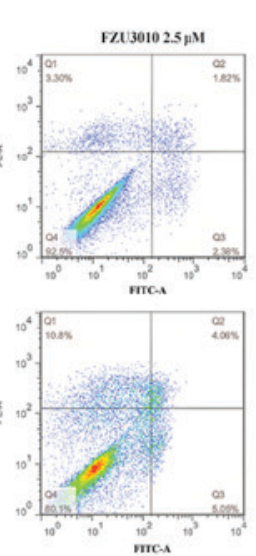

DTX
B
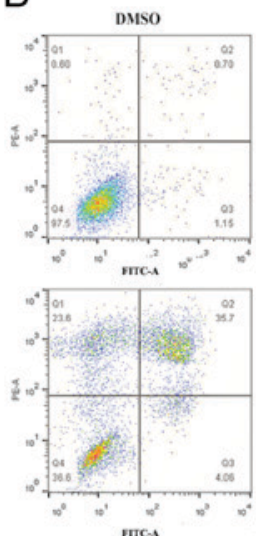

FZU3010 $5 \mu \mathrm{M}$
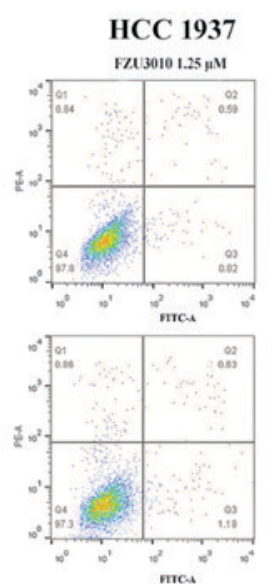

UA $5 \mu \mathrm{M}$
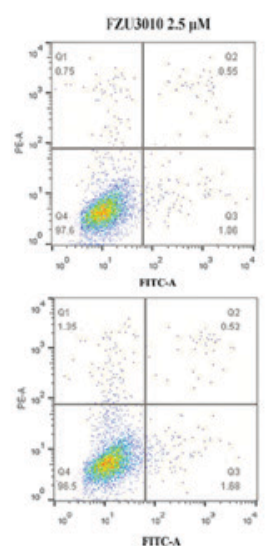

DTX
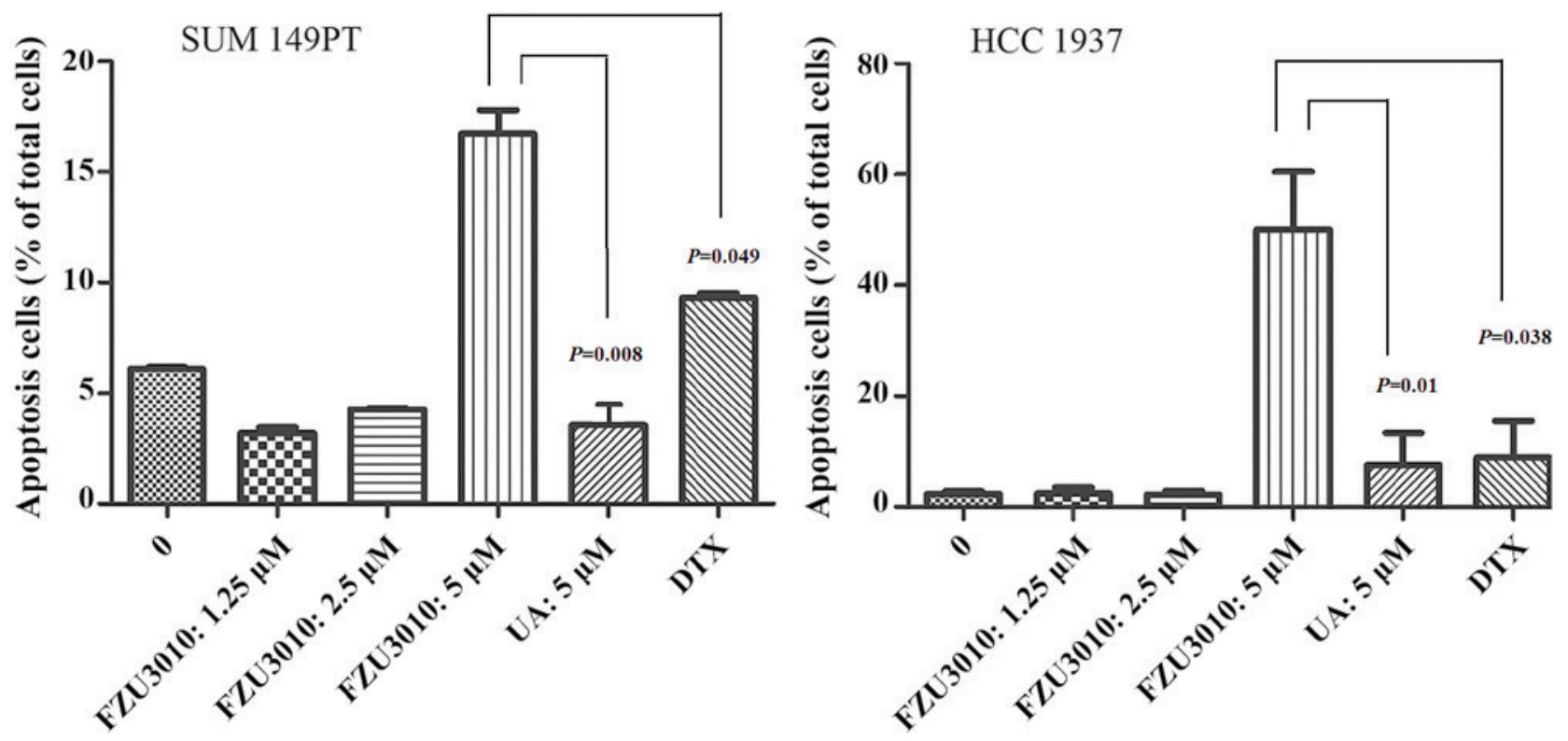

Figure 4. Effect of FZU3010 on cell apoptosis. The percentage of apoptotic cells was determined for cells treated for $48 \mathrm{~h}$ with FZU3010 (0, $1.25,2.5,5 \mu \mathrm{M})$, UA $(5 \mu \mathrm{M})$ and DTX $(5 \mu \mathrm{M})$. (A) Flow cytometry analysis of apoptosis in SUM149PT cells. (B) Flow cytometry analysis of apoptosis in HCC1937 cells. Data are expressed as the mean \pm standard deviation of at least three experiments. FZU3010 induced apoptosis in BC SUM 149PT (P=0.008) and HCC1937 (P=0.01) cells was significantly higher in cells treated with $5 \mu \mathrm{M}$ FZU3010 compared with cells treated with $5 \mu \mathrm{M}$ UA, respectively. Lower left quadrant, viable cells (Annexin V-/PI-); lower right quadrant, early apoptotic cells (Annexin V+/PI-); upper right quadrant, late apoptotic cells (Annexin V+/PI+); upper left quadrant, necrotic cells (Annexin V-/PI+). One-way analysis of variance was used to analyze multiple comparisons between different drug concentrations for the same group. Comparisons indicated by lines. UA, ursolic acid; DTX, doxorubicin.

changes in position 3 and/or 28 of UA were crucial for its cytotoxic activity. In another study, UA-benzylidine derivatives exhibited strong cytotoxic activity and amino acid linkage (37), and UA also caused significant cytotoxic effects in different cancer cell lines. Furthermore, Liu et al (38) proposed that the inclusion of an acyl piperazine moiety at C-28 of UA, keeping the polar group at C-3, significantly increased the antitumor activity of the molecule. To the best of our knowledge, the present study was the first to incorporate piperazine and thiourea into the C-28 and C-3 of UA, with the results indicating that FZU3010 significantly inhibits BC cell viability.

Clinically, it has been suggested that the cell cycle is a primary target for cancer treatment (39). The results of the present study demonstrated that FZU3010 arrested cells in the $\mathrm{G}_{0} / \mathrm{G}_{1}$ phase and prevented them from transitioning to the $S$ phase. $G_{0}$ is the resting phase in which cells stop dividing and leave the cell cycle, while cells prepare energy and material for DNA replication in $\mathrm{G}_{1}$ phase (40). Therefore, arrest of cells in the $G_{0} / G_{1}$ phase resulted in the obstruction of mitosis and cellular DNA synthesis. The role of the UA derivative FZU3010 in inducing apoptosis as part of its anticancer activity was investigated by measuring the percentage of apoptotic SUM149PT and HCC1937 cells following treatment with FZU3010. The results of this treatment indicated that the apoptotic cell rates were highest in cells treated with $5 \mu \mathrm{M}$ FZU3010. The capability of FZU3010 to induce apoptosis in BC SUM 149PT $(\mathrm{P}=0.008)$ and HCC 1937 $(\mathrm{P}=0.01)$ cells was significantly higher in cells treated with $5 \mu \mathrm{M}$ FZU3010 compared with cells treated with $5 \mu \mathrm{M}$ UA. Furthermore, the apoptotic cells in SUM149PT $(\mathrm{P}=0.049)$ and HCC $1937(\mathrm{P}=0.038)$ cells treated with $5 \mu \mathrm{M}$ FZU3010 
were significantly increased compared with cells treated with $5 \mu \mathrm{M}$ DTX.

A number of potential molecular mechanisms underlying the anticancer properties of UA have been elucidated. The results of a previous in vitro study indicated that UA decreases the proliferation of several types of cancer cells by inhibiting the signal transducer and activator of transcription 3 activation pathway and increasing the rate of apoptosis (41). Furthermore, UA upregulates the pro-apoptosis factor Bcl-associated $\mathrm{X}$ and downregulates the anti-apoptosis factor B-cell lymphoma-2, leading to the induction of apoptosis (33). UA-induced apoptosis serves a role in the secretion of cytochrome $c$ in the mitochondrial death pathway (42).

In conclusion, the UA piperazine derivative FZU3010 was designed and synthesized for the current study. The results of subsequent experiments indicate that FZU3010 has the potential to impede $\mathrm{BC}$ cell progression by inducing apoptosis and cell cycle arrest at $S$ and $G_{0} / G_{1}$ phase. However, future studies are required to identify the mechanisms involved in the viability of BC cell lines. Therefore, FZU3010 is a promising therapeutic agent for the treatment of $\mathrm{BC}$.

\section{Acknowledgements}

The current study was supported by grants from the National Natural Science Foundation of China (grant nos. 81272930 and 81322038). The authors also wish to thank Dr Zulqarnain Baloch (Kunming University of Science and Technology, China) for assistance with revising the original manuscript.

\section{References}

1. McGuire S: World Cancer Report 2014. Geneva, Switzerland: World health organization, international agency for research on cancer, WHO press, 2015. Adv Nutr 7: 418-419, 2016.

2. Siegel RL, Miller KD and Jemal A: Cancer statistics, 2015. CA Cancer J Clin 65: 5-29, 2015

3. Wu X, Zou T, Cao N, Ni J, Xu W, Zhou T and Wang X: Plasma homocysteine levels and genetic polymorphisms in folate metablism are associated with breast cancer risk in chinese women. Hered Cancer Clin Pract 12: 2, 2014.

4. Hilakivi-Clarke L, de Assis S, Warri A and Luoto R: Pregnancy hormonal environment and mother's breast cancer risk. Horm Mol Biol Clin Investig 9: 11-23, 2012.

5. Aloraifi F, Boland MR, Green AJ and Geraghty JG: Gene analysis techniques and susceptibility gene discovery in non-BRCA1/BRCA2 familial breast cancer. Surg Oncol 24: 100-109, 2015

6. Tung N, Battelli C, Allen B, Kaldate R, Bhatnagar S, Bowles K, Timms K, Garber JE, Herold C, Ellisen L, et al: Frequency of mutations in individuals with breast cancer referred for BRCA1 and BRCA2 testing using next-generation sequencing with a 25-gene panel. Cancer 121: 25-33, 2015.

7. Castro MA, de Santiago I, Campbell TM, Vaughn C, Hickey TE, Ross E, Tilley WD, Markowetz F, Ponder BA and Meyer KB: Regulators of genetic risk of breast cancer identified by integrative network analysis. Nat Genet 48: 12-21, 2016.

8. Holmes MD, Chen WY, Li L, Hertzmark E, Spiegelman D and Hankinson SE: Aspirin intake and survival after breast cancer. J Clin Oncol 28: 1467-1472, 2010.

9. Bilgin B, Sendur MAN, Şener Dede D, Akinci MB and Yalçın B: A current and comprehensive review of cyclin-dependent kinase inhibitors for the treatment of metastatic breast cancer. Curr Med Res Opin 33: 1559-1569, 2017.

10. Wang J, Dong B, Tan Y, Yu S and Bao YX: A study on the immunomodulation of polysaccharopeptide through the TLR4-TIRAP/MAL-MyD88 signaling pathway in PBMCs from breast cancer patients. Immunopharmacol Immunotoxicol 35: 497-504, 2013
11. Toi M, Masuda N, Ishiguro H, Saji S, Ohno S and Chow LW: Development of breast cancer therapy: Biomarker-driven and response-guided approaches in a neoadjuvant setting. Int J Biol Markers 30: e252-e253, 2015.

12. Ramalingam S, Gediya L, Kwegyir-Afful AK, Ramamurthy VP, Purushottamachar P, Mbatia H and Njar VC: First MNKs degrading agents block phosphorylation of eIF4E, induce apoptosis, inhibit cell growth, migration and invasion in triple negative and Her2-overexpressing breast cancer cell lines. Oncotarget 5: $530-543,2014$.

13. Cargnin ST and Gnoatto SB: Ursolic acid from apple pomace and traditional plants: A valuable triterpenoid with functional properties. Food Chem 220: 477-489, 2017.

14. Mancha-Ramirez AM and Slaga TJ: Ursolic acid and chronic disease: An overview of UA's effects on prevention and treatment of obesity and cancer. Adv Exp Med Biol 928: 75-96, 2016.

15. Hussain H, Green IR, Ali I, Khan IA, Ali Z, Al-Sadi AM and Ahmed I: Ursolic acid derivatives for pharmaceutical use: A patent review (2012-2016). Expert Opin Ther Pat 27: 1061-1072, 2017.

16. Garay CA and Engstrom PF: Chemoprevention of colorectal cancer: Dietary and pharmacologic approaches. Oncology (Williston Park) 13: 89-100, 105, 1999.

17. Ko EY and Moon A: Natural products for chemoprevention of breast cancer. J Cancer Prev 20: 223-231, 2015.

18. Xavier CP, Lima CF, Pedro DF, Wilson JM, Kristiansen K and Pereira-Wilson C: Ursolic acid induces cell death and modulates autophagy through JNK pathway in apoptosis-resistant colorectal cancer cells. J Nutr Biochem 24: 706-712, 2013.

19. Achiwa Y, Hasegawa K, Komiya T and Udagawa Y: Ursolic acid induces Bax-dependent apoptosis through the caspase-3 pathway in endometrial cancer SNG-II cells. Oncol Rep 13: 51-57, 2005.

20. Yang X, Li Y, Jiang W, Ou M, Chen Y, Xu Y, Wu Q, Zheng Q, Wu F, Wang L, et al: Synthesis and biological evaluation of novel ursolic acid derivatives as potential anticancer prodrugs. Chem Biol Drug Des 86: 1397-1404, 2015.

21. Yarla NS, Bishayee A, Sethi G, Reddanna P, Kalle AM, Dhananjaya BL, Dowluru KS, Chintala R and Duddukuri GR: Targeting arachidonic acid pathway by natural products for cancer prevention and therapy. Semin Cancer Biol 41: 48-81, 2016.

22. Wen JH, Wei XH, Sheng XY, Zhou DQ, Peng HW, Lu YN and Zhou J: Effect of ursolic acid on breast cancer resistance protein-mediated transport of rosuvastatin in vivo and vitro. Chin Med Sci J 30: 218-225, 2015.

23. Chen H, Gao Y, Wang A, Zhou X, Zheng Y and Zhou J: Evolution in medicinal chemistry of ursolic acid derivatives as anticancer agents. Eur J Med Chem 92: 648-655, 2015.

24. Gu W, Jin XY, Li DD, Wang SF, Tao XB and Chen H: Design, synthesis and in vitro anticancer activity of novel quinoline and oxadiazole derivatives of ursolic acid. Bioorg Med Chem Lett 27: 4128-4132, 2017.

25. Alves Monteath SAF, Maciel MAM, Vega RG, de Mello H, de Araújo Martins C, Esteves-Souza A, Gattass CR and Echevarria A: Ultrasound-assisted extraction of ursolic acid from the flowers of ixora coccinia Linn (Rubiaceae) and antiproliferative activity of ursolic acid and synthesized derivatives. Pharmacogn Mag 13: 265-269, 2017.

26. Zhang C, Xu SH, Ma BL, Wang WW, Yu BY and Zhang J: New derivatives of ursolic acid through the biotransformation by Bacillus megaterium CGMCC 1.1741 as inhibitors on nitric oxide production. Bioorg Med Chem Lett 27: 2575-2578, 2017.

27. Riaz S, Khan IU, Yar M, Ashraf M, Rehman TU, Shaukat A, Jamal SB, Duarte VC and Alves MJ: Novel pyridine-2,4,6-tricarbohydrazide derivatives: Design, synthesis, characterization and in vitro biological evaluation as $\alpha$ - and $\beta$-glucosidase inhibitors. Bioorg Chem 57: 148-154, 2014.

28. Huang XC, Jin L, Wang M, Liang D, Chen ZF, Zhang Y, Pan YM and Wang HS: Design, synthesis and in vitro evaluation of novel dehydroabietic acid derivatives containing a dipeptide moiety as potential anticancer agents. Eur J Med Chem 89: 370-385, 2015.

29. Shao JW, Dai YC, Xue JP, Wang JC, Lin FP and Guo YH: In vitro and in vivo anticancer activity evaluation of ursolic acid derivatives. Eur J Med Chem 46: 2652-2661, 2011.

30. Zheng QY, Li PP, Jin FS, Yao C, Zhang GH, Zang T and Ai X: Ursolic acid induces ER stress response to activate ASK1-JNK signaling and induce apoptosis in human bladder cancer T24 cells. Cell Signal 25: 206-213, 2013. 
31. Leal AS, Wang R, Salvador JA and Jing Y: Synthesis of novel ursolic acid heterocyclic derivatives with improved abilities of antiproliferation and induction of p53, p21waf1 and NOXA in pancreatic cancer cells. Bioorg Med Chem 20: 5774-5786, 2012.

32. Huang G, Pemp D, Stadtmüller P, Nimczick M, Heilmann J and Decker M: Design, synthesis and in vitro evaluation of novel uni- and bivalent ligands for the cannabinoid receptor type 1 with variation of spacer length and structure. Bioorg Med Chem Lett 24: 4209-4214, 2014.

33. Chavan HV, Adsul LK, Kotmale AS, Dhakane VD, Thakare VN and Bandgar BP: Design, synthesis, characterization and in vitro and in vivo anti-inflammatory evaluation of novel pyrazole-based chalcones. J Enzyme Inhib Med Chem 30: 22-31, 2015.

34. Dong H, Yang X, Xie J, Xiang L, Li Y, Ou M, Chi T, Liu Z, Yu S, Gao Y, et al: UP12, a novel ursolic acid derivative with potential for targeting multiple signaling pathways in hepatocellular carcinoma. Biochem Pharmacol 93: 151-162, 2015.

35. Tu HY, Huang AM, Wei BL, Gan KH, Hour TC, Yang SC, Pu YS and Lin CN: Ursolic acid derivatives induce cell cycle arrest and apoptosis in NTUB1 cells associated with reactive oxygen species. Bioorg Med Chem 17: 7265-7274, 2009.

36. Chen J, Fu H, Wang Z, Yin F, Li J, Hua Y and Cai Z: A new synthetic ursolic acid derivative IUA with anti-tumor efficacy against osteosarcoma cells via inhibition of JNK signaling pathway. Cell Physiol Biochem 34: 724-733, 2014.

37. Dar BA, Lone AM, Shah WA and Qurishi MA: Synthesis and screening of ursolic acid-benzylidine derivatives as potential anti-cancer agents. Eur J Med Chem 111: 26-32, 2016.
38. Liu MC, Yang SJ, Jin LH, Hu DY, Xue W, Song BA and Yang S: Synthesis and cytotoxicity of novel ursolic acid derivatives containing an acyl piperazine moiety. Eur J Med Chem 58: 128-135, 2012.

39. Oura K, Tadokoro T, Fujihara S, Morishita A, Chiyo T, Samukawa E, Yamana Y, Fujita K, Sakamoto T, Nomura T, et al: Telmisartan inhibits hepatocellular carcinoma cell proliferation in vitro by inducing cell cycle arrest. Oncol Rep 38: 2825-2835, 2017.

40. Kang S, Kang MS, Ryu E and Myung K: Eukaryotic DNA replication: Orchestrated action of multi-subunit protein complexes. Mutat Res S0027-S5107, 2017.

41. Pathak AK, Bhutani M, Nair AS, Ahn KS, Chakraborty A, Kadara H, Guha S, Sethi G and Aggarwal BB: Ursolic acid inhibits STAT3 activation pathway leading to suppression of proliferation and chemosensitization of human multiple myeloma cells. Mol Cancer Res 5: 943-955, 2007.

42. Yeh CT, Wu CH and Yen GC: Ursolic acid, a naturally occurring triterpenoid, suppresses migration and invasion of human breast cancer cells by modulating c-Jun N-terminal kinase, Akt and mammalian target of rapamycin signaling. Mol Nutr Food Res 54: 1285-1295, 2010.

This work is licensed under a Creative Commons Attribution-NonCommercial-NoDerivatives 4.0 International (CC BY-NC-ND 4.0) License. 